THE INFLUENCE OF FASHION COMMUNICATION CHANNELS ON THE PSYCHOLOGICAL COMPATIBILITY WITH THE EGYPTIAN SOCIETY AMONG UNIVERSITY STUDENTS

Ola Ali Alwan OMAR*

Department of Garment and Textile, Faculty of Home Economics, Helwan University, Egypt

\begin{abstract}
This research aims to measure levels of psychological compatibility with societal values in dress among university students in view of what media channels represent in transmitting international outfits and their impact on the clothing behavior of individuals within the Egyptian society and through the application of research tools represented in designing a questionnaire as a tool to collect information on age and media channels that It has an effect on the style of clothing with the societal values on a sample of single female students at the university, and the Kai square test and the correlation coefficient (Spearman) were used to verify the research hypotheses. The results showed the existence of a correlation between psychological needs and the level of general compatibility with societal values in clothing as it indicated The presence of significant differences between levels of psychological compatibility and societal values in the good, medium and low-level clothing.

Keywords

Fashion, Communication Channels, Psychological, Egyptian Society, University Students.
\end{abstract}

\title{
Introduction
}

The language of clothing for thousands of years is the first tool that people used to communicate with each other, as a person talks about himself through what he wears, as sociologists have indicated that the prevailing costumes (fashion) are also a symbolic language and a non-verbal system of communication. Alison. (Lurie - 1995) The human behavior, as the researchers see it, is a process of interaction between the individual and society by means of relationships and symbols, which is responsible for forming a network of human relationships that becomes capable of bringing about modification, change and reinforcement. The differentiation and selection situations in which values are formed and it is generally the primary means. For communication between individuals and groups (Saeed Abdul Rahman - 12).

And affirmation of self, love of ownership, improvement of urbanization, rebellion, attention and social harmony. Others added that declaring personality, displaying wealth, imitation, and social unacceptability is illustrated by the dress code and is influenced by external and internal psychological factors. Therefore, the current research has identified the problem at a time when a large proportion of women accept outfits that do not correspond to Egyptian societal values in terms of clothing, and this problem is the result of the influence of communication channels. Fashion and its compatibility with the psychological needs of individuals and due to the different psychological factors of women, the most important of which is age, the current

* Corresponding author: homeecon@helwan.edu.eg 
research has focused on the stage of university students and thus the research problem is determined in the following questions:

1- What are the levels of psychological compatibility with societal values in dress among university students?

2- Is there a statistically significant relationship between media and personal channels and the levels of conformity with societal values in the clothing of university students?

3- What are the media and personal channels that have a moral relationship with the psychological needs of university students?

4 - What is the impression that the university student wants to announce to others about her clothes in terms of compatibility with societal values in terms of clothing (high - medium low)?

\section{The importance of the study:}

- The research contributes to highlighting the role of media channels for fashion, which cannot be denied, whether intentionally or unintentionally, and its effect on provoking the behavior of the girl towards fashion and its role in satisfying the psychological needs related to clothing in unhealthy ways, thus affecting and being affected by it. Demonstrate the role of fashion communication channels and psychological needs in achieving interaction with fashion messages and affecting young fashion consumers.

- Awareness of the clothes of university students about fashion fashions and to benefit from this study in setting up a program to change the dressing behavior towards improved traditional clothes or value consumption rationalization of clothes.

\section{Study objectives:}

1- Measuring levels of conformity with societal values in dress for a sample of university students.

2- Knowing the media and personal channels that have an impact on the university student's dress code.

3- Study the relationship between media channels and the levels of agreement on societal values in dress among university students.

4- Knowing the impression that the university student wants to announce to others about her clothes.

\section{The limits of the study:}

\section{Human limits:}

- This research was applied to female university students in the first and second grades from the age of (18-21) years. 


\section{Objective boundaries:}

- Media and personal channels responsible for promoting fashions in clothes and determining levels of psychological compatibility with societal values in clothing. Spatial boundaries: (Faculties of home economics - Arts - Sciences) in the first and second year of Cairo governorate. Time limits: - The field study was applied in the first semester of the academic year.

The following is a presentation of the tools:

1- A form for gathering information and it consisted of: Personal information: - About age, specialization, school year, and fashion communication channels that have an impact on the students 'dress style, namely:

A- Media channels: TV fashion shows, fashion magazines, stores, display windows, clothes of famous personalities, and mail-order magazines.

B - Personal channels: Moms, girlfriends, seeing others, seller, fashion designer. C - The impression that the student wants to announce to others on her clothes.

2- Psychological needs scale related to clothing: - The researcher prepared a scale that includes eighteen psychological needs, and every need represented by a psychological desire clarifies the intended need without mentioning it, and it was developed to clearly measure adolescent girls 'desires towards the psychological needs related to clothing.

\section{Validity of the scale:}

The researcher relied on the apparent validity of the scale by presenting it to experts in psychology. Stability of scale: The stability of the needs scale was calculated on an exploratory sample of (20 students) by the mid-segment method. And the equation (Spearman and Brown), and the result for the correlation coefficient is $(0,3)$, which indicates a strong correlation. Correcting the scale of psychological needs: - The correction was done as follows: A- He gave the answer (yes) three scores, the answer (to some extent) two degrees, and the answer (no) one degree. B- To arrange psychological needs due to importance (important - medium importance - not important), the grades were divided from grade (2) to grade (1) into three categories, and since the length of the category = range: the number of categories. And range $=r$. The difference between the smallest value and the largest value $(-1)=$, and the number of classes $=$ if the length of the category $=(:=0.66)$.

3-3- Image test to measure compatibility with societal values in clothes: - The researcher prepared a test that measures levels of compatibility with societal values in clothes (high, medium Low) through the outfit designs that the student wants. The scale consists of the first and second sections, in which the students draw the designs that they want, and these desires 
are judged based on the opinion of experts in psychology and sociology. - The first section: An open question for the student to draw three outfits she would like for different occasions to be determined by her, on the mannequin model drawn in front of her to facilitate the drawing process. Clarification of the design parts for the student's calendar (Figure No. 1) Section Two: - A question that is also open to answer it. The student draws on a mannequin model, in front of which she has two outfits, whose designs are suitable for a university student.

\section{References}

- Reham SHALABY, THE CREATIVE ROLE OF PLASTIC ARTS IN THE FACE OF DISCRIMINATION AND VIOLENCE AGAINST WOMEN, International Journal of Humanities and Language Research, Vol. 2, No. 2, 2019, pp. 1-8.

- Wissam Hassan HASHEM, THE DESIGN PERFORMANCE OF INTERNAL SPACES AND ITS RELATIONSHIP TO THE SOCIAL VARIABLE: BAGHDAD CAFES ARE A MODEL, International Journal of Humanities and Language Research, Vol. 2, No. 2, 2019 , pp. 9-19.

- Noura Osama AL-LAITHI, THE EFFECTIVENESS OF A PROPOSED PROGRAM FOR MUSICAL ACTIVITIES TO SPREAD THE VALUE OF TOLERANCE AMONG SOME CHILDREN OF THE FIRST STAGE OF BASIC EDUCATION, International Journal of Humanities and Language Research, Vol. 2, No. 2, 2019, pp. 20-25. 